\title{
Resistência aos fármacos de primeira escolha utilizados no tratamento da tuberculose pulmonar por Mycobacterium tuberculosis
}

\author{
Darliana Pereira dos Santos \\ Farmacêutica graduada pelo Centro Universitário Augusto Motta, Centro de
}

Ciências da Saúde, Farmácia, darliana_rj@oi.com.br

Diana Vasconcellos de Souza

Farmacêutica graduada pelo Centro Universitário Augusto Motta, Centro de Ciências da Saúde, Farmácia, dianasouzafarma@gmail.com

\begin{abstract}
Silvana Rodrigues
Discente de graduação pelo Centro Universitário Augusto Motta, Centro de Ciências da Saúde, Farmácia, Silvana_rodrigues07@yahoo.com.br
\end{abstract}

Kátia Eliane Santos Avelar

Docente do curso de Mestrado Profissional Interdisciplinar em Desenvolvimento Local e curso de graduação em Farmácia - Centro

Universitário Augusto Motta, Kátia.avelar@gmail.com

\begin{abstract}
Resumo: A tuberculose é uma doença infectocontagiosa de evolução crônica, causada por bacilos pertencentes ao gênero Mycobacterium tuberculosis, que são bactérias aeróbias e acometem, principalmente, os pulmões. Esses microrganismos têm como principal porta de entrada no organismo as vias aéreas, e ao chegarem aos alvéolos pulmonares são fagocitados por macrófagos, o que desencadeia um processo inflamatório, pois se multiplicam no interior dos macrófagos e determinam a evolução da doença. Apesar de a tuberculose ser uma doença passivel de cura, na maioria dos casos, na prática, esse processo não acontece devido a numerosas impropriedades terapêuticas que podem ocorrer. Outro fator importante para o insucesso terapêtico é o abandono do tratamento por parte do paciente, o que constitui um fator determinante para a seleção de cepas resistentes aos antimicrobianos. Diante desse cenário, o presente estudo teve como foco discutir a resistência apresentada pelo Mycobacterium tuberculosis frente aos fármacos de primeira escolha para o tratamento da tuberculose pulmonar.
\end{abstract}

Palavras-chave: Mycobacterium tuberculosis, tuberculose pulmonar, resistência a antimicrobianos.

\section{Profile of Patients Undergoing Percutaneous Coronary}

Revista de Saúde, Vassouras, v. 3, n. 1, p. 13-25, jan./jun., 2012 


\title{
Intervention in the Hemodynamics Service of University Hospital South Fluminense, Vassouras - RJ
}

\begin{abstract}
Tuberculosis is an infectious disease of chronic evolution, caused by bacilli of the genus Mycobacterium tuberculosis, which are aerobic bacteria, affecting mainly the lungs. These microorganisms have the main entrance in the body airway. When you reach the pulmonary alveoli are phagocytosed by macrophages, triggering an inflammatory process. Multiply inside macrophages determine the progression of the disease. Although tuberculosis should be susceptible to cure a disease, in most cases, in practice this process does not happen, due to numerous therapeutic inaccuracies which may occur. Another important factor for therapeutic failure is noncompliance with treatment by the patient which is a determining factor for selection of strains resistant to antibiotics. Against this backdrop, this study focused on discussing the main resistance of the Mycobacterium tuberculosis of first choice drugs for treatment of pulmonary tuberculosis.
\end{abstract}

Keywords: Mycobacterium tuberculosis, pulmonary tuberculosis, antimicrobial resistance.

\section{Introdução}

A tuberculose é uma doença infectocontagiosa, cuja transmissão se dá através das vias áreas. Tem evolução crônica e é causada no homem por espécies do gênero Mycobacterium dentre as quais se destaca o M. tuberculosis (Cunha et al 2007).

Apesar de a tuberculose ser uma doença antiga ainda existem poucos fármacos efetivos para o seu tratamento. Como consequência da falta de investimento no combate a essa doença, seu tratamento apresenta problemas como efeitos indesejáveis, tratamento prolongado e surgimento de microrganismos resistentes, o que representa um grave problema de saúde pública mundial (Kaiser et al 2007).

Um dos problemas mais importantes no tratamento da tuberculose consiste na resistência bacteriana. A principal razão para o desencadeamento da resistência aos fármacos utilizados no tratamento desta doença consiste no abandono do tratamento por parte do paciente [Medeiros e Andrade 2008].

O surgimento de cepas resistentes é preocupante, uma vez que pode tornar a doença sem tratamento. Por essa razão é imprescindível o conhecimento das diferentes estratégias desenvolvidas pelo Mycobacterium tuberculosis para se tornarem resistentes às drogas utilizadas, além do desenvolvimento de técnicas diagnósticas que possam detectar essas resistências [Cunha e Frota 2005], com vistas a um melhor controle da doença.

A tuberculose é transmitida de pessoa a pessoa, principalmente por meio do ar. A fala, 
o espirro, a tosse de um doente de tuberculose pulmonar bacilífera lança no ar gotículas de tamanhos variados que contêm o bacilo no seu interior. As gotículas mais pesadas depositam-se rapidamente no solo, entretanto, as mais leves podem permanecer em suspensão por diversas horas. Os bacilos que se depositam nas roupas, lençóis, copos e outros objetos dificilmente se dispersarão em aerossóis e, por isso, não desempenham papel importante na transmissão da doença [Ministério da Saúde 2005].

A estratégia de controle da tuberculose tem sido elaborada por programas governamentais (Rossetti et al 2002). O controle da tuberculose reside no diagnóstico precoce e tratamento efetivo, além da vacinação e quimioprofilaxia [Medeiros e Andrade 2008].

Apesar da disponibilidade de tratamento altamente eficaz há décadas, a tuberculose continua a ser um importante problema de saúde global. Desde 1993, a Organização Mundial de Saúde (OMS) declarou a tuberculose uma emergência de saúde pública mundial [Organização Mundial de Saúde 2011].

No Brasil, de acordo com dados do Ministério da Saúde, nove em cada 100 pacientes que iniciam o tratamento não o levam até o fim. O máximo tolerável, segundo a Organização Mundial da Saúde (OMS), é quase a metade disso: cinco em cada 100. Embora a taxa de incidência da tuberculose venha caindo no país nas últimas décadas, atualmente é de 37,7 casos para 100 mil habitantes, e ainda morrem a cada ano cerca de 4.800 brasileiros em função da doença, na maior parte das vezes porque o paciente não concluiu o tratamento [Ministério da Saúde 2012].

\section{Tratamento}

O tratamento dos pacientes bacilíferos é prioritário no controle da tuberculose, uma vez que permite controlar as fontes de infecção. A associação medicamentosa adequada, as doses corretas e o uso, por tempo suficiente, com supervisão da tomada dos medicamentos, são os meios utilizados para evitar a persistência bacteriana e o desenvolvimento de resistência às drogas, assegurando a cura do paciente [Ministério da Saúde 2005].

Foram necessários 15 anos após a importante descoberta de Fleming para que Selman Waksman descobrisse, em 1944, a estreptomicina (SM), produzida também por uma bactéria, Streptomyces griseus, que foi o primeiro antibiótico capaz de atuar de maneira eficaz no combate à tuberculose [Souza e Vasconcelos 2005]. Desta forma, a estreptomicina foi administrada, com resultados notáveis, em um paciente com tuberculose pulmonar progressiva que não respondiam aos meios curativos disponíveis na época (Cunha et al 2007).

Após a descoberta da (SM), novos fármacos foram utilizados com sucesso, com destaque para a isoniazida (INH), em 1952; a rifampicina (RMP), em 1965; o etambutol (EMB), sintetizado em 1968 e a pirazinamida (PZA) sintetizada em 1936, porém só utilizada em 1970 [Souza e Vasconcelos 2005].

As drogas antituberculose são classificadas como de primeira e de segunda linhas, de acordo com a eficácia, a atividade e o risco de produzir reações adversas. Em geral, as drogas de segunda linha são mais tóxicas e, em alguns casos, menos eficazes que as de 
primeira [Snyder e Finch 1994].

Os fármacos comumente chamados de primeira escolha são a primeira opção no tratamento, podem ser empregados com sucesso na maioria dos pacientes e incluem INH, RMP, PZA e EMB. Os fármacos de segunda escolha são normalmente utilizados em caso de falência aos fármacos de primeira escolha, administram-se a SM e a etionamida, ou devido à resistência do bacilo, com emprego de diferentes tipos de canamicina isoladas de Streptomyces kanamyceticus, cicloserina, ácido p-aminosalicílico (PAS), amicacina, etionamida, tioacetazona, clorofazimina e terizidona [Souza e Vasconcelos 2005].

Classicamente, o tratamento da tuberculose compreende duas fases: a de ataque e a de manutenção. O primeiro e imediato objetivo a ser atingido pela farmacoterapia é ganhar o controle da infecção. Este é alcançado com a morte da grande população existente nas cavidades sem permitir a sobrevida de mutantes drogas-resistentes [Medeiros e Andrade 2008]. Na fase de ataque, (a inicial do tratamento), para prevenir a falência do tratamento devido à resistência adquirida, associam-se drogas de alto poder bactericida. Conseguese, desse modo, reduzir rápida e drasticamente a população bacilar e a proporção de mutantes resistentes, além de assegurar a eliminação de germes com resistência primária. A fase de manutenção (prolongamento da terapia) tem como objetivo a eliminação dos germes persistentes e a prevenção de recaídas e recidivas [Ministério da Saúde 2002].

No Brasil, os esquemas de tratamento da tuberculose são padronizados desde 1979 pelo Ministério da Saúde. Na última norma técnica, publicada em outubro de 2009, o tratamento indicado para todos os casos novos de tuberculose pulmonar e extrapulmonar, assim como para todos os casos de recidiva e de retorno após abandono, é a utilização de quatro drogas em um único comprimido com dose fixa combinada: rifampicina, isoniazida, pirazinamida e etambutol por dois meses e, numa segunda fase, isoniazida e rifampicina por mais quatro meses (esquema 2RHZE/4RH) (Arbex et al 2010).

\section{Mecanismo de ação dos compostos utilizados no tratamento da tuberculose Isoniazida}

A atividade antimicobacteriana da isoniazida foi descoberta em 1952 e ainda hoje a INH é considerada como fármaco-base da quimioterapia antituberculose, tanto para infecções ativas quanto para aquelas latentes. Isso é devido à excelente atividade, ao baixo custo e à relativamente baixa toxicidade deste fármaco [Andrade 2008].

O mecanismo de ação da isoniazida envolve a inibição de ácidos micólicos, componentes essenciais da parede celular do bacilo (Cunha et al 2007). A isoniazida é um pró-fármaco, ativado pela enzima catalase-peroxidase (KatG) micobacteriana que converte a isoniazida em um metabólito ativo [Petri2010], produzindo radicais reativos de oxigênio (superóxido, peróxido de hidrogênio e peroxinitrato) e radicais orgânicos que inibem a formação de ácido micólico da parede celular, causando danos ao DNA (Ácido desoxirribonucléico) e subsequente morte do bacilo (Andrade et al 2008). A isoniazida ativada pela catalaseperoxidase, liga-se ao produto do gene inhA, a enoil-ACP redutase do ácido graxo sintase II, que converte os ácidos graxos insaturados em ácidos graxos saturados na via de biossíntese do ácido micólico [Petri 2010]. 
A isoniazida é solúvel em água [Snyder e Finch 1994], prontamente absorvida pelo trato gastrintestinal e é amplamente distribuída por todos os tecidos e líquidos corporais, incluindo o líquido cefalorraquidiano (LCR) (Rang et al 2007). Penetra fácil no material caseoso e as concentrações plasmáticas máximas são alcançadas dentro de 1 a 2 horas após a ingestão oral de doses habituais [Petri 2010].

A metabolização é hepática, por acetilação pela N-acetiltransferase, que produz acetilisoniazida e ácido isonicotínico (Arbex et al 2010). A isoniazida é eliminada na urina parcialmente como um fármaco inalterado e parcialmente na forma acetilada ou inativa de outra maneira (Rang et al 2007).

\section{Rifampicina}

A rifampicina (RMP) é o fármaco de escolha para o tratamento da tuberculose. É um fármaco bactericida que atua tanto no bacilo em crescimento e metabolicamente ativo quanto na fase estacionária, com metabolismo reduzido (Arbex et al 2010). É um fármaco bactericida para micobactérias, capaz de atuar tanto intra como extracelularmente e eficaz também para microrganismos Gram-positivos e Gram-negativos (Harvey et al 1998).

A rifampicina inibe a transcrição gênica da micobactéria por bloqueio da RNA polimerase DNA dependente, através da formação de um complexo fármaco-enzimático estável, levando à supressão da iniciação da formação da cadeia (mas não de seu alongamento), o que impede a síntese de RNA mensageiro (RNAm) e de proteína pelo bacilo, produzindo morte celular. Mais especificamente a subunidade $\beta$ dessa enzima complexa constitui o local de ação da rifampicina [Petri 2010]; (Arbex et al 2010).

A rifampicina é bem absorvida pelo trato gastrintestinal e alcança níveis sanguíneos máximos em 2 a 4 horas após a ingestão. Penetra bem nos tecidos e alcança níveis terapêuticos nos pulmões, nas secreções brônquicas, no liquor, no líquido pleural, no fígado, na bile, na urina, nas cavernas tuberculosas e nos macrófagos. A rifampicina é desacetilada no fígado [Snyder e Finch 1994]. Aproximadamente 85\% do medicamento é metabolizado no fígado através de enzimas microssomais integrantes do sistema citocromo P450. A excreção se faz por via biliar (60-65\%). Parte da rifampicina é excretada, não metabolizada e reabsorvida no intestino, aumentando progressivamente o nível sérico do fármaco. Uma menor parte do fármaco é excretada na urina (Arbex et al 2010).

\section{Pirazinamida}

A pirazinamida é o análogo pirazínico sintético da nicotinamida [Petri 2010]. É um derivado do ácido nicotínico, com estrutura molecular similar a da isoniazida, mas sem resistência cruzada com a mesma. A droga foi sintetizada em 1936 e é utilizada como tuberculostático desde 1952 (Arbex et al 2010). A pirazinamida (PZA) é inativa em $\mathrm{pH}$ neutro, porém é tuberculostática em $\mathrm{pH}$ ácido. Ela é efetiva contra microrganismos intracelulares nos macrófagos porque, após a fagocitose, os microrganismos ficam contidos nos fagolisossomos, onde o pH é baixo (Rang et al 2007). A pirazinamida deve ser hidrolisada enzimaticamente para originar o ácido pirazinóico, que é a forma ativa da 
droga (Harvey et al 1998).

É bactericida e tem uma potente ação esterilizante, principalmente em meio ácido no interior dos macrófagos e em áreas de inflamação aguda. Na lesão pulmonar por tuberculose, os bacilos fagocitados pelos macrófagos apresentam seu crescimento inibido pelo ambiente ácido do interior dos fagolisossomos. O crescimento também se encontra inibido nas zonas inflamatórias da parede cavitária pelo pH ácido. Esses bacilos, denominados persistentes e em fase de multiplicação esporádica, são os responsáveis pela recaída bacteriológica da tuberculose. A pirazinamida é o medicamento mais eficaz para eliminar essa população. Essa atividade da pirazinamida, denominada esterilizante, permitiu a redução do esquema de tratamento para seis meses (Arbex et al 2010).

O alvo da pirazinamida parece ser o gene do ácido graxo sintase I das micobactérias, envolvido na biossíntese do ácido micólico [Petri 2010]. Seu mecanismo de ação ainda é pouco conhecido. Supõe-se que a pirazinamida penetre no bacilo de forma passiva, seja convertida em ácido pirazinóico pela pirazinamidase bacteriana e atinja altas concentrações no citoplasma bacteriano em virtude de um ineficiente sistema de efluxo. $\mathrm{O}$ acúmulo de ácido pirazinóico diminui o $\mathrm{pH}$ intracelular a níveis que causam a inativação de enzimas, como o ácido graxo sintase I, fundamental para a síntese dos ácidos graxos e, em consequência, prejudicando a biossíntese do ácido micólico (Arbex et al 2010).

A pirazinamida é bem absorvida pelo trato gastrintestinal e distribui-se amplamente por todo o organismo. Atinge concentração máxima plasmática em 2 horas. A meia-vida plasmática é de 9 a 10 horas [Petri 2010]. A metabolização é hepática e 70\% da droga é excretada pela urina ( $3 \%$ de forma não metabolizada), principalmente por filtração glomerular (Arbex et al 2010). A pirazinamida é hidrolisada a ácido pirazinóico e, subsequentemente, hidroxilada a 5-hidroxipirazinóico, o principal produto de excreção [Petri 2010].

\section{Etambutol}

O etambutol é um composto hidrossolúvel termoestável [Petri 2010]. Foi sintetizado em 1961 e é utilizado no tratamento da tuberculose desde 1966. Atua sobre os bacilos intra e extracelulares, normalmente os de multiplicação rápida. Sua ação é bacteriostática nas doses usuais (Arbex et al 2010). A importância de seu emprego reside em sua capacidade de suprimir o crescimento da maioria dos bacilos resistentes à isoniazida e estreptomicina (Cunha et al 2007).

O etambutol (EMB) interfere na biossíntese de arabinogalactano, principal polissacarídeo da parede celular da micobactéria. Atua inibindo a enzima arabinosil transferase codificada pelo gene embB, que media a polimerização de arabinose para arabinogalactano (Arbex et al 2010).

Cerca de 75 a $80 \%$ de uma dose oral de etambutol são absorvidos pelo trato gastrintestinal, atingindo o pico sérico em 2 a 4 horas. O fármaco apresenta meia vida de 3 a 4 horas [Petri 2010]. Uma parte da droga (20-30\%) se une às proteínas plasmáticas. Tem ampla distribuição corporal, exceto no líquido cefalorraquidiano (LCR) com a meninge íntegra. 
A metabolização é hepática (Arbex et al 2010). Em 24 horas, 75\% de uma dose oral são excretados de modo inalterado na urina; até $15 \%$ são excretados na forma de dois metabólitos: um aldeído e um derivado do ácido dicarboxílico. O fármaco é excretado por secreção tubular, além da filtração glomerular [Petri 2010].

\section{Estreptomicina}

A estreptomicina, isolada em 1944, foi o primeiro fármaco eficaz empregado no tratamento da tuberculose. Tem atividade bactericida contra micobactérias extracelulares (Cunha et al 2007). A destruição bacteriana depende da concentração: quanto maior a concentração maior a taxa de destruição das bactérias. Caracteriza também por um efeito pós-antibiótico, isto é, persistência de uma atividade bactericida residual após a queda da concentração sérica abaixo da concentração inibitória mínima (CIM), sendo a duração desse efeito dependente também da concentração do fármaco [Henry 2010].

A estreptomicina (SM) inibe a síntese protéica ao ligar-se de maneira irreversível à subunidade $30 \mathrm{~S}$ do ribossomo bacteriano, interferindo na integridade da membrana celular (Arbex et al 2010).

A via de administração é parenteral. Por administração intramuscular a absorção é completa, atingindo o pico sérico máximo em 30 a 90 minutos. A ligação às proteínas plasmáticas é baixa (aproximadamente 10\%). Em um período de 24 horas, 80 a 98\% do fármaco é excretado por via renal, através de filtração glomerular, como droga inalterada. A meia-vida da estreptomicina é de 2 a 3 horas (Arbex et al 2010).

\section{Mecanismos de resistência aos fármacos de primeira escolha utilizados no tratamento da tuberculose pulmonar}

As micobactérias utilizam uma série de estratégias para desenvolver resistência a drogas. As principais são: diminuição da permeabilidade e aumento do efluxo da droga, degradação ou inativação das drogas através de enzimas e modificações no alvo da droga. Essas modificações podem ser adquiridas através de plasmídios ou em mutações cromossômicas. Todavia a resistência adquirida pelo M. tuberculosis é devido a mutações cromossômicas, sendo a resistência a múltiplas drogas refletida pelo acúmulo de várias mutações em vários genes independentes [Medeiros e Andrade 2008].

Os tipos de resistência do M. tuberculosis podem ser resumidos em: natural (decorrente de mutação espontânea, independentemente de exposição prévia a fármacos); inicial (observada no momento em que o paciente se apresenta para tratamento, com resistência a um ou mais fármacos. Inclui os pacientes com resistência primária ou adquirida, sobre os quais não se conhecem informações de tratamentos anteriores); primária (observada em pacientes sabidamente não tratados antes, infectados por uma fonte doente com forma resistente); adquirida ou secundária (resultante de uso prévio de medicação de forma inadequada) (Dalcomo et al 2007). As micobactérias desenvolvem resistência a múltiplas drogas pelo acúmulo de mutações individuais em vários genes, cada um dos quais é responsável pela resistência a um antibiótico em particular. Na tabela 1 podemos observar 
Resistência aos fármacos de primeira escolha utilizados no tratamento da tuberculose pulmonar por Mycobacterium tuberculosis

Darliana Pereira dos Santos - Diana Vasconcellos de Souza - Silvana Rodrigues - Kátia Eliane Santos Avelar

as alterações genéticas associadas ao desenvolvimento de resistência aos antimicrobianos de primeira linha (Arráiz et al 2005).

Tabela 1: Drogas de primeira linha e mecanismos moleculares de resistência ao M. tuberculosis

\begin{tabular}{|c|c|c|c|}
\hline $\begin{array}{c}\text { Agente } \\
\text { antimicrobiano }\end{array}$ & $\begin{array}{l}\text { Mecanismo de ação da } \\
\text { droga }\end{array}$ & Genes afetados e mecanismos de resistência & $\begin{array}{c}\text { Frequência } \\
\text { de mutações }\end{array}$ \\
\hline Isoniazida & $\begin{array}{l}\text { Inibição da síntese de } \\
\text { ácidos micólicos }\end{array}$ & $\begin{array}{l}\text { KatG (catalase-peroxidase): mutações neste } \\
\text { gene impede a ativação da isoniazida; } \\
\text { InhA (enoil-ACP redutase): mutações na } \\
\text { InhA induz aumento da expressão do gene e } \\
\text { níveis elevados da enzima enoil redutase em } \\
\text { quantidades que superam o poder inibitório da } \\
\text { isoniazida }\end{array}$ & $50-68 \%$ \\
\hline Rifampicina & $\begin{array}{l}\text { Inibição da transcrição de } \\
\text { genes por interação com } \\
\text { a RNA polimerase }\end{array}$ & $\begin{array}{l}\text { rpoB (subunidade B da RNA polimerase): } \\
\text { mutações neste gene impede a interação da } \\
\text { rifampicina com a RNA polimerase. }\end{array}$ & $96-98 \%$ \\
\hline Pirazinamida & Não elucidado & $\begin{array}{l}\text { pncA (enzima pirazinamidase): mutações no } \\
\text { gene pncA determina uma diminuição na } \\
\text { produção de ácido pirazinóico, metabólito } \\
\text { ativo da pirazinamida }\end{array}$ & $72-97 \%$ \\
\hline Etambutol & $\begin{array}{l}\text { Inibição da síntese de } \\
\text { componentes da parede } \\
\text { celular das micobactérias } \\
\text { (arabinogalactanos) }\end{array}$ & $\begin{array}{l}\text { embABC (enzimas arabinosil transferase): } \\
\text { mutações neste gene ou aumento da expressão } \\
\text { permitem a síntese contínua de } \\
\text { arabinogalactanos }\end{array}$ & $47-65 \%$ \\
\hline Estreptomicina & $\begin{array}{l}\text { Inibição da síntese de } \\
\text { proteínas }\end{array}$ & $\begin{array}{l}\text { rpsl (subunidade ribossomal S12) } \\
\text { rrs (RNA ribossomal 16S): mutações nestes } \\
\text { genes impedem a interação com a } \\
\text { estreptomicina }\end{array}$ & $\begin{array}{l}64-67 \% \\
8-21 \%\end{array}$ \\
\hline
\end{tabular}

\section{Resistência à Isoniazida}

A isoniazida (INH) é uma pró-droga que, quando capturada pelo bacilo, é ativada pela catalase-peroxidase, de modo que a ausência de atividade da catalase, devido a mutações no gene katG que codifica esta enzima, é um dos mecanismos de resistência à isoniazida (Arráiz et al 2005).

A resistência a INH pode ser predita como resultado de mutações que diminuem o nível de expressão do gene e reduz a atividade da peroxidase ou a peroxidação do produto. Em algumas cepas altamente resistente à INH ocorre deleção do gene katG do cromossomo, todavia, a maioria das cepas mostra uma mutação pontual no gene que altera a atividade da proteína KatG. A mutação pode estar localizada na região $\mathrm{N}$-terminal ou C-terminal da proteína. A enzima catalase para tornar-se ativada necessita ligar-se ao um cofator metálico, que geralmente é o zinco ou o ferro. Portanto, mutações que alterem a região N-terminal, contribuem para que a ligação estabelecida seja ineficaz e com isso a atividade da enzima fica prejudicada, alterando a sensibilidade à isoniazida. As mais frequentes substituições são encontradas nos códons 315 (Ser-Thr) e 463 (Arg-Leu) [Cunha e Frota 2005]. Estas mutações são responsáveis por aproximadamente $50 \%$ dos casos de INH resistentes em amostras clínicas (Arráiz et al 2005).

A InhA é uma proteína transportadora de grupos enoil-ACP redutase (ACP- proteína acil carregadora) que é importante na síntese dos ácidos micólicos. Uma expressão exagerada 
do gene inhA, assim como uma mutação em regiões promotoras no gene inhA, gera cepas com resistências à isoniazida [Cunha e Frota 2005].

Existem muitos pontos inexplicados em relação à ação da INH no M. tuberculosis, entretanto, existem cepas resistentes onde tais desses genes não estão envolvidos. Contudo, cerca de $80 \%$ da resistência a INH encontrados em isolados clínicos são atribuídos ao gene katG [Cunha e Frota 2005].

\section{Resistência à Rifampicina}

A resistência microbiana à rifampicina deve-se a uma alteração no alvo desse fármaco, a RNA-polimerase DNA dependente e, na maioria dos casos, a resistência é produzida por mutações entre os códons 507 e 533 do gene rpoB da polimerase. As mutações reduzem a ligação do fármaco à polimerase [Petri 2010].

Cerca de 95\% das mutações ocorrem nos códons 516, 526 e 531, o que possibilitou o desenvolvimento de teste diagnósticos para detectar a resistência à rifampicina [Cunha $\mathrm{e}$ Frota 2005].

A resistência à rifampicina é pouco comum, porém tem aumentado ultimamente, alertando para o desenvolvimento de linhagens MDR (multidroga resistente). Dificilmente a resistência à rifampicina ocorre isolada. Na maioria dos casos, está associada a outros fármacos, principalmente à isoniazida. Nesse contexto a resistência à rifampicina pode ser assumida como um marcador para a TB MDR (tuberculose multidroga resistente) (Rossetti et al 2002).

\section{Resistência à pirazinamida}

$\mathrm{O}$ mecanismo de resistência à pirazinamida $(\mathrm{PZA})$ proposto até o momento é a deficiência da pirazidamidase (Pzase), com consequente perda da capacidade de ativar o antibiótico (Arráiz et al 2005).

A diminuição da atividade da atividade da enzima pirazinamidase (Pzase), codificada pelo gene pncA, está relacionada com a resistência a (PZA). No M.bovis que é naturalmente resistente a PZA, existe mutação no códon $\mathrm{C} 169 \mathrm{G}$ do gene pncA, que torna o M. bovis naturalmente resistente a droga. De modo similar, a mutação no gene pncA é o mais importante mecanismo de resistência do M. tuberculosis á PZA. A natureza das mutações no pncA incluem substituições de aminoácidos, inserções ou pequenas deleções de nucleotídeos, como também, mutações no promotor do gene [Cunha e Frota 2005].

Mais de 70\% dos isolados de M. tuberculosis resistentes à PZA apresentaram mutações no gene pncA, que codifica a enzima Pzase a qual converte o fármaco PZA em sua forma ativa (Rossetti et al 2002).

As substituições nos aminoácidos ocorrem preferencialmente na região 3 a 17, 61 a 76 e 132 a 142. Essas regiões representam cerca de 22\% da proteína PncA. O alinhamento das sequencias de aminoácidos de varias espécies de microrganismos revela que estas três regiões contem resíduos altamente conservados, o que confirma a idéia de que essas 
regiões podem ser estruturalmente e ou cataliticamente importantes para a atividade da enzima PZA. Uma das hipóteses para a baixa atividade observada em alguns mutantes deve-se à conformação inadequada da proteína ou à instabilidade da proteína Pzase [Cunha e Frota 2005].

\section{Resistência ao etambutol}

Os efeitos do etambutol (EMB) são extremamente seletivos e foram propostos como alvo de ação a enzima arabinosil transferase. Existem três classes de arabinosil transferase: classe I, classe II e classe III. As classes I e II apresentam baixa afinidade com o EMB enquanto a classe III apresenta alta afinidade. O gene emb codifica vários homólogos da arabinosil transferase: EmbA, EmbB e EmbC [Cunha e Frota 2005].

As alterações genéticas identificadas até o momento estão concentradas em uma região designada como embCAB, incluindo genes que codificam para a arabinosiltransferases, enzimas envolvidas na síntese de componentes exclusivos da parede celular de micobactérias (Arráiz et al 2005).

O EMB se liga ao centro ativo da enzima e, portanto, a produção excessiva da enzima EmbB resulta em resistência à droga. Foram encontradas mutações em múltiplos códons que resultaram em dois, três ou quatro aminoácidos diferentes na proteína EmbB, sendo esta proteína provavelmente de localização transmembrana, que tem atividade importante na síntese de ácidos micólicos do M. tuberculosis [Cunha e Frota 2005].

\section{Resistência à estreptomicina}

A resistência à estreptomicina $(\mathrm{SM})$ em $\mathrm{M}$. tuberculosis ocorre por mutações no alvo do fármaco, mais especificamente nos ribossomos. O principal sitio de mutação é o gene rpsL, que codifica a proteína ribossomal $\mathrm{S} 12$, em que ocorrem mutações resultando na substituição de um único aminoácido (Rossetti et al 2002).

Um segundo mecanismo de resistência ocorre por alterações no gene que codifica o RNA 16S em duas regiões diferentes (Rossetti et al 2002).

Uma pequena fração dos bacilos resistentes à SM tem mutações nas alças do RNAr 16S, que é codificada pelo gene rrs. Entretanto, em cerca de 30\% dos isolados resistentes à SM não se encontram mutações nos genes rpsL ou rrs. Estudos nesse grupo mostraram menor grau de resistência e levantaram suspeitas de que tenham alterações na permeabilidade da parede celular. Possivelmente, mecanismos adicionais ainda desconhecidos sejam responsáveis por 24-40\% das resistências clínicas [Campos 1999].

\section{Resistência a Multidrogas}

Enzimas citocromo P450, geralmente, são encontradas em células de mamíferos e raramente são encontradas em bactérias. O M. tuberculosis possui cerca de 20 dessas enzimas. Essas enzimas poderiam ser usadas pelo bacilo da tuberculose na metabolização 
rápida das drogas e conseqüente desenvolvimento de multirresistência. Essas enzimas presentes no M. tuberculosis podem representar um alvo potencial para desenvolvimento de novas drogas [Cunha e Frota 2005].

Internacionalmente, resistência a multidrogas é definida como resistência à rifampicina e à isoniazida. No Brasil, contudo, optou-se por uma definição operacional de tuberculose multidroga resistente: qualquer forma clínica da doença na qual o exame bacteriológico detecta resistência in vitro à, pelo menos, rifampicina, isoniazida e a mais uma ou mais das drogas componentes do tratamento. Possivelmente, a tuberculose multidroga-resistente é o resultado da acumulação de diferentes mutações independentes e não fruto de um único evento [Campos 1999].

Os pacientes portadores de bacilos resistentes à isoniazida e rifampicina e de bacilos resistentes à isoniazida, rifampicina e outro fármaco de primeira linha ou pacientes com falência ao esquema básico constituem um grupo de doentes classificados como portadores de tuberculose multirresistente. Para esses casos, foi proposto um esquema constituído por estreptomicina, etambutol, terizidona, pirazinamida e uma quinolona. $\mathrm{Na}$ impossibilidade de se utilizar a estreptomicina, esta é substituída por amicacina. Portadores de tuberculose extensivamente resistente devem ser encaminhados para centros de referência terciários e utilizarem esquemas individualizados com fármacos de reserva, que incluem capreomicina, moxifloxacina, ácido p-aminossalicílico e etionamida (Arbex et al 2010).

\section{Conclusão}

A resistência bacteriana torna-se cada vez mais crescente. Medidas de controle devem ser adotadas, o que inclui o desenvolvimento de novas drogas, melhor controle das infecções, e principalmente, conservação do atual arsenal terapêutico, por meio da educação quanto ao uso dos antimicrobianos. Devido a esta razão é imprescindível o conhecimento das diferentes estratégias moleculares desenvolvidas pelo $\mathrm{M}$. tuberculosis que lhe conferem resistência às drogas utilizadas, e é também uma das principais causas da tuberculose multirressistente às drogas.

É importante mencionar que nenhum agente quimioterápico novo contra a tuberculose foi introduzido nos últimos 40 anos. Uma vacina uniformemente efetiva ainda não foi desenvolvida, o que torna preocupante o surgimento de cepas resistentes, ressaltando que o M. tuberculosis apresenta uma frequência acentuada de mutações genéticas, o que determina uma resistência natural às drogas.

\section{Referências}

Andrade, C. H. et al. (2008). Abordagem racional no planejamento de novos tuberculostáticos: inibidores da inhA, enoil-ACP redutase do M.tuberculosis. Revista Brasileira de Ciências Farmacêuticas, volume 44, n. ${ }^{\circ}$ 2, abr/jun, 2008.

Arbex, M. A. et al. (2010). Drogas antituberculose: interações medicamentosas, efeitos 
adversos e utilização em situações especiais. Parte 1: Fármacos de primeira linha. Jornal Brasileiro de Pneumologia, 2010; 36 (5): 626-640.

Arráiz, N. et al. (2005) Resistência a drogas em M. tuberculosis: Bases moleculares. AVFT volume 24, número 1. Caracas, 2005.

Campos, H. S. (1999). Mycobacterium tuberculosis resistente: de onde vem a resistência? Boletim de Pneumologia Sanitária, volume 7, n. ${ }^{\circ} 1-$ jan/jun - 1999.

Cunha, F. A. e Frota, C. C. (2005). Bases Moleculares da Resistência do Mycobacterium tuberculosis as Drogas usadas no Tratamento da Tuberculose - Revisão. RBAC, volume 37(3): 157-161, 2005.

Cunha, T. N. et al. (2007). Em busca de lipossomas inteligentes para a administração de drogas para a tuberculose. Boletim Epidemiológico Paulista, volume 4, n. ${ }^{\circ}$ 39, março de 2007.

Dalcomo, M. P. et al. (2007). Tuberculose multirresistente no Brasil: histórico e medidas de controle. Revista Saúde Pública, 2007; 41 (Supl. 1): 34-42.

Harvey, R. A. et al. (1998). Fármacos antimicobactérias. Farmacologia Ilustrada. 2. edição. Porto Alegre: Artmed Editora, 1998.

Kaiser, C. R. et al. (2007). Oxazolidinonas: uma nova classe de compostos no combate a tuberculose. Revista Brasileira Farmacêutica, 84 (2): 83-88, 2007.

Medeiros, J. B. B. e Andrade, V. M. (2008). Tuberculose: do tratamento convencional à farmacogenética de medicamentos. Arquivos Catarinenses de Medicina, volume 37, n. ${ }^{\circ}$ 4, 2008.

Ministério da Saúde. (2002). Fundação Nacional de Saúde. Controle da Tuberculose: uma proposta de integração ensino-serviço. 5. edição. Rio de janeiro, 2002.

Ministério da Saúde. (2005). Secretaria de Vigilância em Saúde. Guia de Vigilância Epidemiológica. Série A. Normas e Manuais Técnicos. 6. edição. Brasília, 2005.

Ministério da Saúde reforça campanha contra tuberculose. Disponível em: <http://www. vermelho.org.br>. Acesso em: 05/03/2012.

Organização Mundial de Saúde. (2011). Controle global da tuberculose, 2011.

Petri, Jr. W. A. (2010). Quimioterapia da tuberculose, complexo Mycobacterium avium e hanseníase, in: Goodman e Gilman. As bases farmacológicas da terapêutica. 11. a edição. Porto Alegre: AMGH, 2010.

Rang, H. P. et al. (2007). Fármacos antibacterianos. Farmacologia. 6. edição. Rio de Janeiro: Elsevier, 2007.

Rossetti, M. R. L. et al. (2002). Tuberculose resistente: revisão molecular. Revista Saúde Pública, 2002; 36 (4): 525-532.

Snyder; I.S e Finch; R. G. (1994). Drogas utilizadas na Tuberculose e na Lepra, in: CRAIG; C. R.; STITZEL; R. E. Farmacologia Moderna. 4. ${ }^{a}$ edição. Rio de Janeiro: Editora Guanabara Koogan S.A., 1994. 
Resistência aos fármacos de primeira escolha utilizados no tratamento da tuberculose pulmonar por Mycobacterium tuberculosis

Darliana Pereira dos Santos - Diana Vasconcellos de Souza - Silvana Rodrigues - Kátia Eliane Santos Avelar

Souza, M. V. N. e Vasconcelos, T. R. A. (2005). Fármacos no combate à tuberculose: passado, presente, futuro. Química Nova, Rio de Janeiro, volume 28, n. ${ }^{\circ}$ 4, 2005. 